\title{
Study of Raw and Recycled Polyethylene Terephthalate by Meaning of TGA and Computer Simulation
}

\author{
Bouzid Latifa 1 , Fouddad Fatma Zohra, and Hiadsi Said \\ Laboratoire de Microscope Electronique et Science des Matériaux, Université des Sciences et de la Technologie d'Oran \\ Mohamed Boudiaf, B.p 1505 El M’Naouar, 3100 Oran, Algeria \\ Correspondence should be addressed to Bouzid Latifa; malek_latifa@yahoo.fr
}

Received 12 August 2020; Revised 14 September 2020; Accepted 19 September 2020; Published 5 October 2020

Academic Editor: Vijay K. Thakur

Copyright (C) 2020 Bouzid Latifa et al. This is an open access article distributed under the Creative Commons Attribution License, which permits unrestricted use, distribution, and reproduction in any medium, provided the original work is properly cited.

\begin{abstract}
The pyrolysis method of both raw and recycled polyethylene terephthalate was studied using the nonisothermal thermogravimetric analysis (TGA) at different five heating rates $(10,15,20,25$, and $30 \mathrm{~K} / \mathrm{min})$ for each element. Without using any mathematical equations, the kinetic parameters of polyethylene terephthalate pyrolysis were obtained by applying the modified distributed activation energy model (DAEM). Furthermore, the glass transition temperature (Tg) of polyethylene terephthalate was simulated using the computer simulation with different methods. The effect of energy in the Tg process was enhanced. The mechanical properties of polyethylene terephthalate were computed. Our simulated values were compared with available data in literature.
\end{abstract}

\section{Introduction}

Decomposition of polymers is an important process [1]. The study of the pyrolysis process of polymers by using nonisothermal thermogravimetric analysis (TGA) was widely known in the last years [2-4]. Compared to other methods, pyrolysis procedure has more strong points: (i) requires the lowest temperature, (ii) without the need of oxygen, and (iii) fabrication of outstanding quality oil [5]. A good knowledge of the pyrolysis process will be useful and helpful element to the design and operation of pyrolysis reactors with developed efficiency [6]. To find the kinetic parameters of pyrolysis process, different models have been found [7]. Among them, we can mention the distributed activation energy model (DAEM) that is used in this paper.

Miura [8] and Miura and Maki [9] found a new procedure based on the modification of the classic DAEM method to get the activation energy $\left(E_{a}\right)$ and the frequency factor $\left(k_{0}\right)$ by following simple steps [10].

Recycled polymers have many advantages, such us the preserving of the environment, saving energy, and its low cost. However, due to what is common about recycled plastics that it is not good and loses its physical properties, we have compared some properties of the raw PET with the properties of recycled PET, using both of the experimental and the computer simulation. In the best of our knowledge, these elements have been not studied in other paper with the same procedure, which makes our work new in the field of polymer study.

Polyethylene terephthalate (PET) is a thermoplastic polymer vastly used in the form of fiber, sheet, and film [11]. Polyethylene terephthalate (PET) has good mechanical strength, great stability with body fluids, and strong radiation resistance, which make it appropriate for sterilization [12].

PET is widely used in many fields such as electrical engineering, water and soft drink bottle industries, and transportation and building industries, due to its physical and chemical properties $[13,14]$.

Many TGA tests of our polymers under five heating rates $(10,15,20,25$, and $30 \mathrm{~K} / \mathrm{min})$ were conducted, and the found results were used to find the values of pyrolysis kinetic parameters (the activation energy $\left(E_{0}\right)$ and the dependent frequency factor $\left.\left(k_{0}\right)\right)$ by using the distributed activation energy model (DAEM) modified by Miura and Maki.

In order to improve our work, the glass transition temperature $(\mathrm{Tg})$ of PET was studied by meaning of molecular 
dynamic (MD) simulation. The results obtained by MD simulation were compared with the experimental results in other papers, the simulated values of other works, and with the results calculated by using the semiempirical method Synthia [15]. In addition, the role of some energy components (the potential energy, the kinetic energy, and the total energy components) in the glass transition temperature ( $\mathrm{Tg}$ ) process was studied, and the predicted elastic properties by the MD simulations of PET at $300^{\circ} \mathrm{K}$ were computed.

Many previous works have proved that molecular dynamic simulation gives results which are near to the experimental values in the study of the properties of materials [16-18].

\section{Experimental}

In this work, the raw polyethylene terephthalate (PET) and the recycled PET were studied by using nonisothermal thermogravimetric procedure for five different heating rates $(10,15,20,25$, and $30 \mathrm{~K} / \mathrm{min})$ for each dry sample of $1 \mathrm{~g}$. The pyrolysis experiences were conducted in thermogravimetric analyzer TGA Q500 from TA Instruments. In the goal to maintain the raw PET and recycled PET in inert atmosphere and make sure that there is no oxygen during all pyrolysis process, a flow of nitrogen of $60 \mathrm{ml} / \mathrm{min}$ is applied. The temperature profile fixed to the TGA contains two basic steps: (i) a drying process of the element at $105^{\circ} \mathrm{C}$ for a during of $20 \mathrm{~min}$ and (ii) the pyrolysis process happen when increasing the temperature of the polymer in the oven up to $750^{\circ} \mathrm{C}$ at a fixed heating rate in inert atmosphere. In this study, uncertainty in the degree of temperature of our devices is $\pm 1^{\circ} \mathrm{C}$, the temperature precision is $\pm 0.1^{\circ} \mathrm{C}$, the weighing precision of the nonisothermal thermogravimetric analysis is $\pm 0.01 \%$, and its mass measurement sensitivity is $0.1 \mu \mathrm{g}[6,7]$.

Without using mathematic, we can obtain the very proper kinetic parameters (the distribution curve of activation energy $f(E)$ and the activation energy dependent frequency factor $\left.\left(k_{0}\right)\right)$ of polymer pyrolysis by applying the distributed activation energy model (DAEM) modified by Miura [8] and Miura and Maki [9]. This procedure is based on the modification of the classic DAEM method to get the activation energy $\left(E_{a}\right)$ and the frequency factor $\left(k_{0}\right)$ by following a few points:

(a) Finding the devolatilization rate for different heating rates

(b) Compute and trace the curve $\ln \left(a / T^{2}\right)$ versus $1 / T$ at each rate of devolatilization

(c) Finding the activation energy $\left(E_{a}\right)$ and the frequency factor $\left(k_{0}\right)$ from the Arrhenius plots at each rate of devolatilization

(d) Trace the values of activation energy $\left(E_{a}\right)$ versus the rate of devolatilization to obtain the function $f\left(E_{a}\right)$

(e) Predict other values of devolatilization rate curves for other heating rates. [10]

\section{Simulations Methods}

In this paper, all molecular dynamic (MD) simulations were computed by using the Materials Studio6.0 software package of Accelrys, Inc. [19].

Molecular mechanics (MM) correspond to a set of empirical procedure for calculation of molecular structures and different physical properties using atoms as the basic elements. It analyzes the progress of a force field (ff) in which polymer chain can be relaxed (energy minimization or geometry optimization) or in which they can be in movement according to classical motional equations (MD) [20]. The choice of the force field plays an important role in influencing on the value of the final results. In our study, COMPASS has been chosen as a force field.

The PET polymer structure with 20 repeat units is embedded in a cell with periodic boundary conditions (Figure 1). To relax our polymer chain, a drastic minimization is applied by using Conjugate Gradient with 20000 iterations to confirm that our polymer chain does not contain any undesirable interactions.

To ensure the molecular relaxation of PET polymer chain, a series of molecular dynamics of 100 ps (using Verlet-leapfrog algorithm) with the canonical ensemble NPT were applied [21]. First, a NVT dynamic is applied in order to stabilize our polymer chain. Then, the dilatometric procedure is applied to get the glass transition temperature ( $\mathrm{Tg}$ ), applying the ensemble NPT by fixing the pressure to $0.0001 \mathrm{GPa}$ and the temperature at $300^{\circ} \mathrm{K}$, to find the density of equilibrium that it is employed to get the specific volume. This last can be employed to compute the glass transition temperature (Tg) of PET. Our structure will overheat from $300^{\circ} \mathrm{K}$ to $800^{\circ} \mathrm{K}$ and decreases from $800^{\circ} \mathrm{K}$ to $200^{\circ} \mathrm{K}$ with a step of $50^{\circ} \mathrm{K}$ during $100 \mathrm{ps}$ for each temperature.

Furthermore, the elastic properties of the raw polyethylene terephthalate (PET) were studied using the molecular dynamic MD simulation at $300^{\circ} \mathrm{K}$. The Smart algorithm was used, and COMPASS was chosen as a force field. The bulk modulus and shear modulus were simulated by using the Reuss, Voigt, and Hill methods. The internal stress tensor is calculated by using the relation:

$$
\sigma=\frac{-1}{V}\left[\left(\sum_{i=1}^{n} a_{i}\left(v_{i} v_{i}^{T}\right)\right)+\left(\sum_{i<k} p_{i i} w_{i k}^{T}\right)\right],
$$

where $i$ is the number of particle; $a_{i}, v_{i}$, and $w_{i}$ are the mass, velocity of the particle, and force acting on the particle, respectively; $V$ is the volume of the structure $[18,22]$.

\section{Results and Discussion}

4.1. Pyrolysis Process. Figure 2 shows the devolatilization curves versus temperature of both raw PET (a) and recycled PET (b) for the five different heating rates $(10,15,20,25$, and $30 \mathrm{~K} / \mathrm{min}$ ).

From the curve obtained in Figure 2, a $\ln \left(a / T^{2}\right)$ versus 1/T plot of structures: raw PET (a) and recycled PET (b) for each heating rate, at different values of the devolatilization 


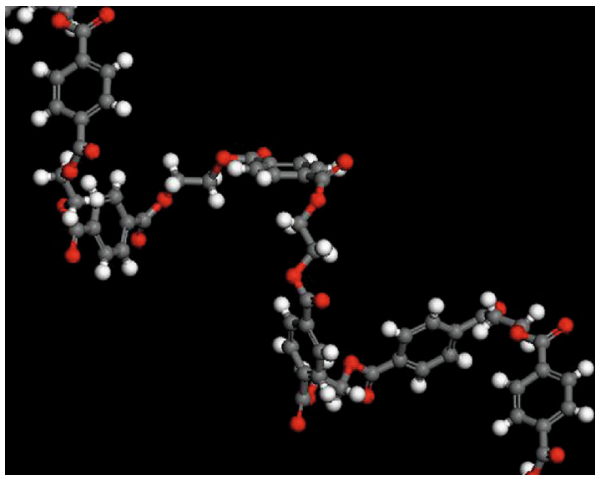

(a)

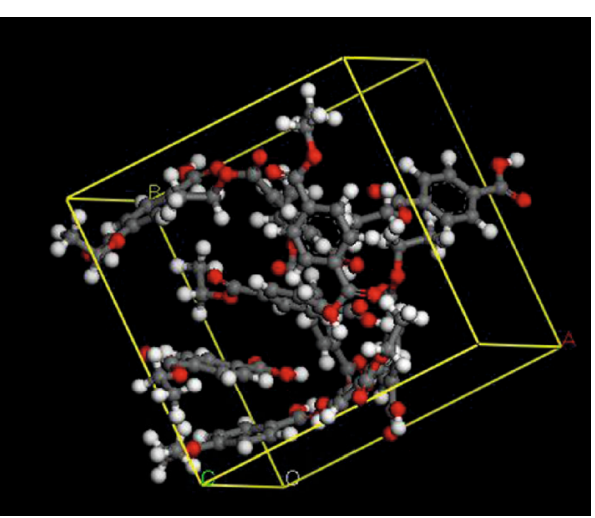

(b)

FIGURE 1: Molecular model of PET before (a) and after construction (b).
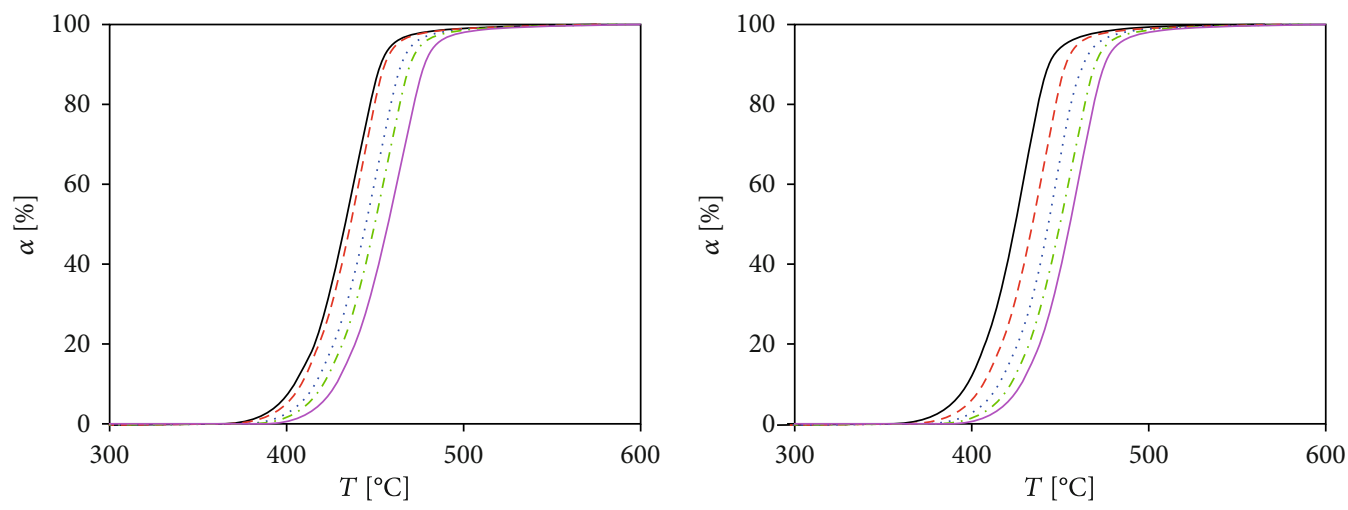

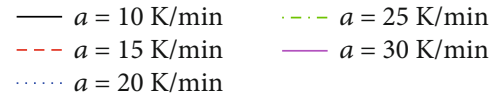

(a)

$$
\begin{aligned}
-a & =10 \mathrm{~K} / \mathrm{min} \quad \cdots a=25 \mathrm{~K} / \mathrm{min} \\
---a & =15 \mathrm{~K} / \mathrm{min} \quad-a=30 \mathrm{~K} / \mathrm{min} \\
\cdots \cdots a & =20 \mathrm{~K} / \mathrm{min}
\end{aligned}
$$

(b)

Figure 2: Devolatilization rate of the PET (a) and recycle PET (b) samples.

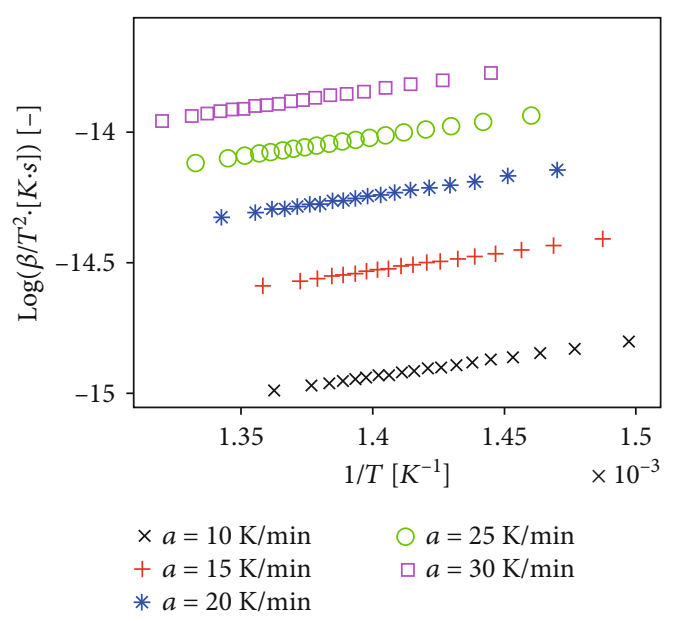

(a)

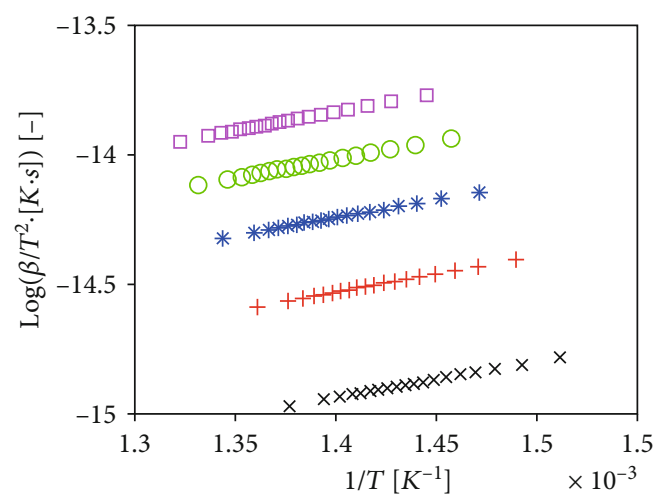

$$
\begin{array}{rlrl}
\times a & =10 \mathrm{~K} / \mathrm{min} & & \bigcirc a=25 \mathrm{~K} / \mathrm{min} \\
+a=15 \mathrm{~K} / \mathrm{min} & & \square a=30 \mathrm{~K} / \mathrm{min}
\end{array}
$$$$
\text { * } a=20 \mathrm{~K} / \mathrm{min}
$$

(b)

FIgURE 3: Arrhenius plot obtained using conversion rate intervals of 5\% for the PET (a) and recycled PET (b) samples. 


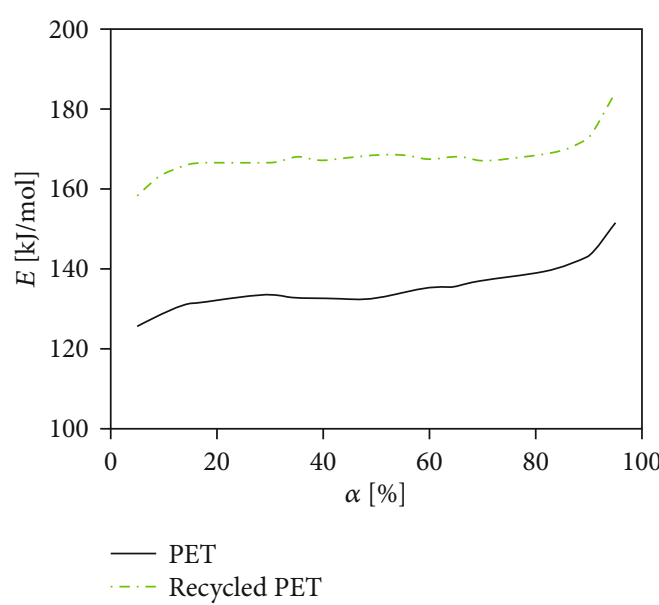

(a)

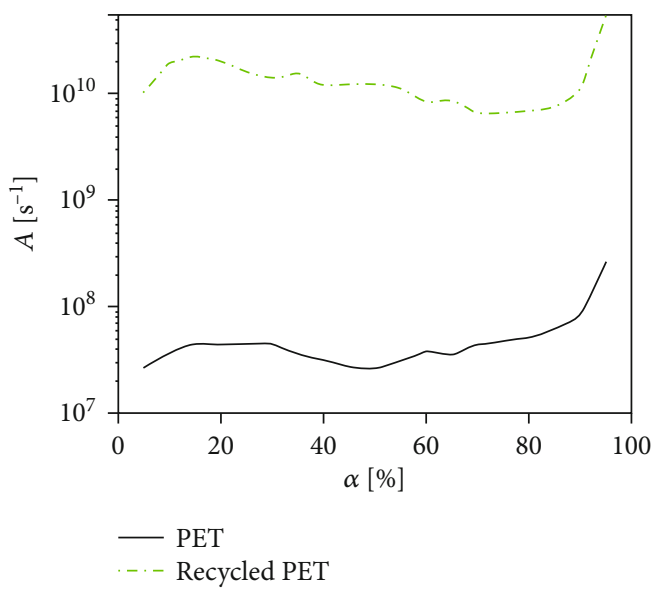

(b)

FIGURE 4: Kinetic parameters: (a) activation energy and (b) frequency factor.

rate was plotted in Figure 3 by using conversion rate range of $5 \%(5 \%-95 \%)$ to give a good visualization. The Arrhenius plots of raw PET and recycled PET are almost similar.

The activation energy $\left(E_{a}\right)$ and the frequency factor $\left(k_{0}\right)$ of our structures can be given from the slope and intercept in the Arrhenius plots at each rate of devolatilization using the linear fitting and with the two relations:

$$
\begin{aligned}
& E_{a}-m \cdot R, \\
& k_{0}=-m \cdot \exp (n-0.6075),
\end{aligned}
$$

where $T$ is the temperature and $R$ the universal constant.

The activation energy $\left(E_{a}\right)$ (a) and the frequency factor $\left(k_{0}\right)$ (b) obtained from the raw PET and recycled PET samples are shown in Figure 4. We can remark that the activation energy $\left(E_{a}\right)$ found for the raw PET is in the range of 120$150 \mathrm{~kJ} / \mathrm{mol}$, and the frequency factor $\left(k_{0}\right)$ was in the range of $10^{7}-10^{9} \mathrm{~s}^{-1}$, which is in accordance with the results obtained in other studies $[23,24]$. For recycled PET, the activation energy $\left(E_{a}\right)$ found is in the range of $159-185 \mathrm{~kJ} / \mathrm{mol}$, and the frequency factor $\left(k_{0}\right)$ was in the range of $10^{10}$ $10^{11} \mathrm{~s}^{-1}$.

\subsection{Molecular Dynamic Simulation}

4.2.1. Glass Transition Temperature ( $\mathrm{Tg}$ ). The glass transition temperature $(\mathrm{Tg})$ of a polymer is an essential phenomenon which can have different values. There is no exact method to find the glass transition temperature [25]. Currently, the most used procedure is the free volume theory proposed by Fox and Flory [26].

Figure 5 shows the curve of the specific volume versus the temperature of the raw PET. The specific volume ( $\mathrm{sp}$ ) is obtained from the NPT trajectory file. By the analysis of the curve of specific volumes vs. the temperature, we detect the simulated glass transition temperature of PET (about $358.34^{\circ} \mathrm{K}$ ) that is little higher than the experimental value $\left(346.6^{\circ} \mathrm{K}\right.$ [27]) and smaller than the simulated value of the

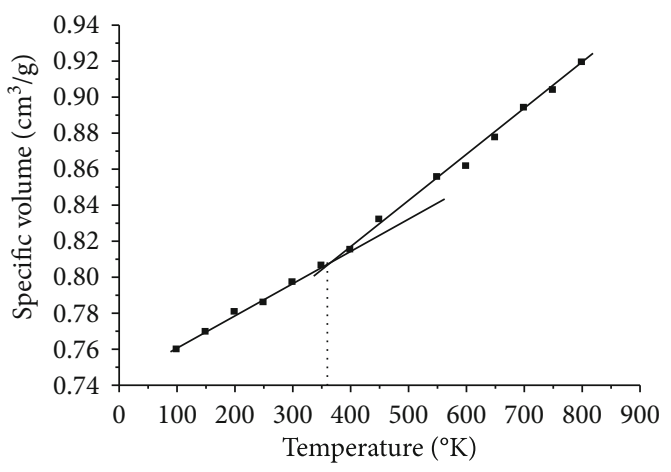

FIgUre 5: The specific volume vs. temperature for PET.

glass transition temperature (Tg) of PET in other papers (about $362^{\circ} \mathrm{K}[28]$ ).

In addition, the glass transition temperature $(\mathrm{Tg})$ of PET was computed by using the semiempirical method Synthia. Table 1 shows the simulated glass transition temperature of PET by using the molecular dynamic (MD) simulation, Synthia and the simulated value of other study, and experimental glass transition temperatures of PET.

4.2.2. Roles of the Energy Components in the Tg Process. In order to study the roles of the different elements in the glass transition temperature process, some energy components versus the temperature are shown in Figure 6. Many previous works have studied the role of the energy components in the transition glass temperature process for different structures [30, 31].

In this paper, the potential energy, the kinetic energy, and the total energy components decrease linearly with temperature decreasing, and there are no any breaks at any point in the curves of the energies versus the temperature. This shows that the potential energy and the kinetic energy play important roles during the glass transition process. 
TABLE 1: Simulated and experimental Tg of PET.

\begin{tabular}{lcccc}
\hline & Simulated Tg (MD) & Simulated Tg (Synthia) & Experimental Tg & Other simulated Tg \\
\hline PET & $358.34^{\circ} \mathrm{K}$ & $368.16^{\circ} \mathrm{K}$ & $346.6^{\circ} \mathrm{K}^{\mathrm{a}}, 338^{\circ} \mathrm{K}^{\mathrm{b}}$ & $361.9^{\circ} \mathrm{K}^{\mathrm{c}}$ \\
\hline
\end{tabular}

${ }^{\mathrm{a}}$ Value from Ref [27]. ${ }^{\mathrm{b}}$ Value from Ref [29]. ${ }^{\mathrm{c}}$ Value from Ref [28].

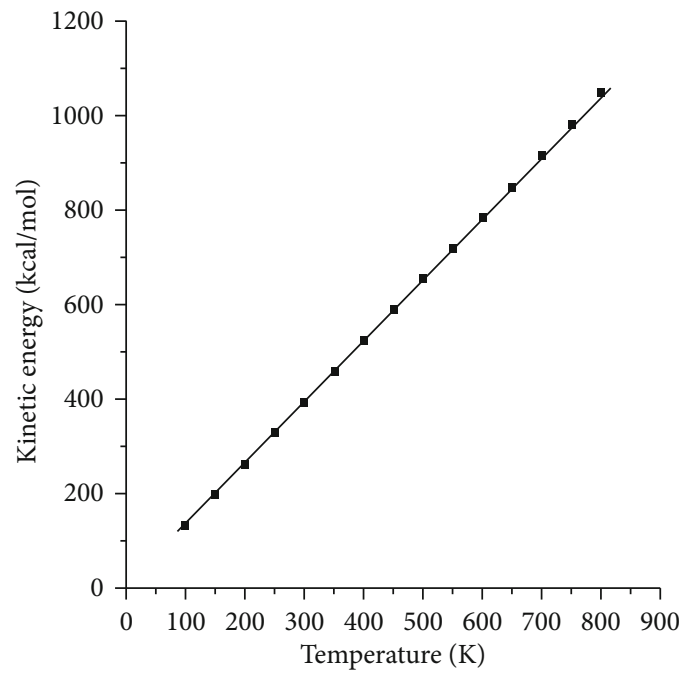

- Kin energy

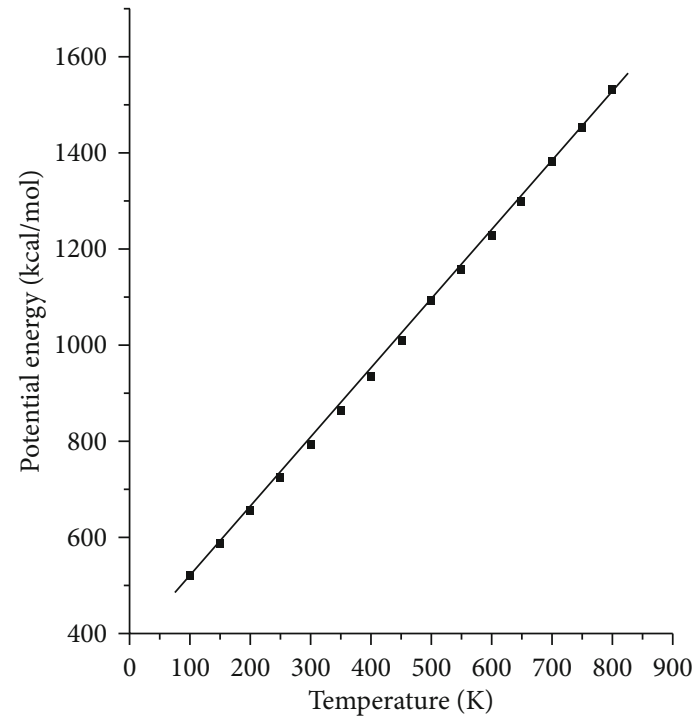

- Pot energy

(a)

(b)

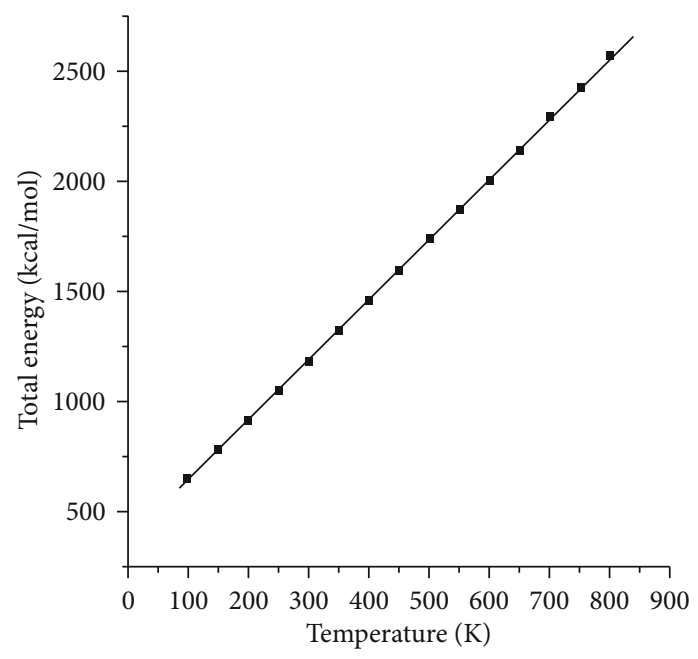

- Total energy

(c)

FIGURE 6: Curves of some energy components vs. temperature for the raw PET: (a) kinetic energy; (b) potential energy; (c) total energy.

4.2.3. Mechanical Properties. The predicted elastic properties by the molecular dynamic (MD) simulations with COMPASS force field of PET at $300^{\circ} \mathrm{K}$ are given in Table 2 .

By the analysis of the table, we can remark that our value of Young's modulus $(E)$ of PET is near to the available result with a difference of just $0.03 \mathrm{GPa}$. Both of bulk modulus and Poisson's ratio are very near to the values obtained in other works. The shear modulus $(G)$ simulated in our study is a little different to the found shear modulus in other paper.

\section{Conclusion}

Thermogravimetric curves were used to study the pyrolysis process of raw PET and recycled PET by using DAEM simplified by Miura and Maki. Devolatilization rate of the PET and recycle PET samples is almost similar. The activation energy $\left(E_{a}\right)$ found for the raw PET is in the range of 120$150 \mathrm{~kJ} / \mathrm{mol}$, and the frequency factor $\left(k_{0}\right)$ was in the range of $10^{7}-10^{9} \mathrm{~s}^{-1}$, which is in accordance with the results 
TABLE 2: Young's modulus $(E)$, shear modulus $(G)$, bulk modulus $(K)$, and Poisson's ratio $(v)$ at $300^{\circ} \mathrm{K}$ of PET.

\begin{tabular}{lcccccccc}
\hline & \multicolumn{4}{c}{ Elastic properties $(\mathrm{GPa})$ at $300 \mathrm{~K}$} \\
& \multicolumn{4}{c}{ Our results } & \multicolumn{5}{c}{ Other results } \\
\hline Polymer & $E$ & $G$ & $K$ & $v$ & $E$ & $G$ & $K$ & $v$ \\
PET & 2.7 & 0.95 & 6.43 & 0.41 & $3^{\mathrm{a}}$ & $0.02^{\mathrm{b}}$ & $6.3 \pm 0.2^{\mathrm{c}}$ & $0.43^{\mathrm{d}}$ \\
\hline
\end{tabular}

${ }^{\mathrm{a}}$ Value from Ref [32]. ${ }^{\mathrm{b}}$ Value from Ref [33]. ${ }^{\mathrm{c}}$ Value from Ref [34]. ${ }^{\mathrm{d}}$ Value from Ref [35].

obtained in other studies. For recycled PET, the activation energy $\left(E_{a}\right)$ found is in the range of $159-185 \mathrm{~kJ} / \mathrm{mol}$, and the frequency factor $\left(k_{0}\right)$ was in the range of $10^{10}-10^{11} \mathrm{~s}^{-1}$. From all above results, it can be concluded that the recycled PET is more cohesive than the raw PET contrary to popular belief.

Furthermore, the glass transition temperature $(\mathrm{Tg})$ of PET was studied by meaning of molecular dynamic (MD) simulation. By the analysis of the curve of specific volumes vs. the temperature, we find that the Tg of PET is $358.34^{\circ} \mathrm{K}$ that is between the experimental value $\left(346.6^{\circ} \mathrm{K}\right)$ and the simulated value of $\mathrm{Tg}$ of PET in other study (about $362^{\circ} \mathrm{K}$ ). In the addition, the role of some energy components was analyzed. The potential energy and the kinetic energy play an important role during the glass transition process. Our simulated results of mechanical properties of PET were very near to the available values in literature.

From the comparison of our simulated results with other values in different papers, we can conclude that our methods of simulation give good results.

\section{Data Availability}

No data were used to support this study.

\section{Conflicts of Interest}

All the authors declare no conflict of interest.

\section{Acknowledgments}

This work has been partially supported by the BIOLAB in the Department of Thermal Engineering and Fluid Mechanics, University Carlos III of Madrid.

\section{References}

[1] R. Cao, S. Naya, R. Artiaga, A. García, A. Varela, and A. Varela, "Logistic approach to polymer degradation in dynamic TGA," Polymer Degradation and Stability, vol. 85, no. 1, pp. 667-674, 2004.

[2] S. Singh, C. Wu, and P. T. Williams, "Pyrolysis of waste materials using TGA-MS and TGA-FTIR as complementary characterisation techniques," Journal of Analytical and Applied Pyrolysis, vol. 94, pp. 99-107, 2012.

[3] Z. Ma, N. G. JianghaoXie, and C. Quan, "Pyrolysis behaviors of oilfield sludge based on Py-GC/MS and DAEM kinetics analysis," Journal of the Energy Institute, vol. 92, pp. 1053-1063, 2018.
[4] M. C. Celina, "Review of polymer oxidation and its relationship with materials performance and lifetime prediction," Polymer Degradation and Stability, vol. 98, pp. 2419-2429, 2013.

[5] Z. Chen, M. Hu, X. Zhu et al., "Characteristics and kinetic study on pyrolysis of five lignocellulosic biomass via thermogravimetric analysis," Bioresource Technology, vol. 192, pp. 441-450, 2015.

[6] A. Soria-Verdugo, E. Goos, N. García-Hernando, and U. Riedel, "Analyzing the pyrolysis kinetics of several microalgae species by various differential and integral isoconversional kinetic methods and the Distributed Activation Energy Model," Algal Research, vol. 32, pp. 11-29, 2018.

[7] A. Soria-Verdugo, N. Garcia-Hernando, L. M. Garcia-Gutierrez, and U. Ruiz-Rivas, "Analysis of biomass and sewage sludge devolatilization using the distributed activation energy model," Energy Conversion and Management, vol. 65, pp. 239-244, 2013.

[8] K. Miura, "A new and simple method to estimate $f(E)$ and $\mathrm{k}_{0}(\mathrm{E})$ in the distributed activation energy model from three sets of experimental data," Energy \& Fuels, vol. 9, pp. 302307, 1995.

[9] K. Miura and T. Maki, "A simple method for estimating $f(E)$ and $\mathrm{k}_{0}(\mathrm{E})$ in the distributed activation energy model," Energy \& Fuels, vol. 12, p. 864, 1998.

[10] A. Soria-Verdugo, E. Goos, A. Morato-Godino, N. GarciaHernando, and U. Riedel, "Pyrolysis of biofuels of the future: Sewage sludge and microalgae - thermogravimetric analysis and modelling of the pyrolysis under different temperature conditions," Energy Conversion and Management, vol. 138, pp. 261-272, 2017.

[11] F. Dubelley, E. Planes, C. Bas, E. Pons, B. Yrieix, and L. Flandin, "Predictive durability of polyethylene terephthalate toward hydrolysis over large temperature and relative humidity ranges," Polymer, vol. 142, pp. 285-292, 2018.

[12] B. Gupta, J. G. Hilborn, I. Ebisson, and P. Frey, "Plasmainduced graft polymerization of acrylic acid onto poly(ethylene terephthalate) films," Journal of Applied Polymer Science, vol. 81, no. 12, pp. 2993-3001, 2001.

[13] G. Güclü and M. Orbay, "Alkyd resins synthesized from postconsumer PET bottles," Progress in Organic Coatings, vol. 65, no. 3, pp. 362-365, 2009.

[14] H. Liu, R. Wang, and X. Xu, "Thermal stability and flame retardancy of PET/magnesium salt composites," Polymer Degradation and Stability, vol. 95, pp. 1466-1470, 2010.

[15] G. Nirav, R. Roopali, S. Arun et al., "Design and development of a poly(acrylonitrile-co-methyl methacrylate) copolymer to improve the viscoelastic and surface properties critical to scratch resistance," RSC Advances, vol. 44, pp. 37933-37937, 2016.

[16] F. Ahmed and N. S. Akbar, "Numerical simulation of the forced convective nanofluid flow through an annulus sector duct," Chinese Journal of Physics, vol. 55, no. 4, pp. 1400-1411, 2017.

[17] R. Muhammad, M. Tariq, H. M. Rafique, M. Tanveer, and F. H. Syed, "Design of a negative refractive index material based on numerical simulation," Chinese Journal of Physics, vol. 54, pp. 587-591, 2016.

[18] N. Berrahou, A. Mokaddem, B. Doumi, S. Hiadsi, A. Beldjoudi, and A. Boutaous, "Investigation by molecular dynamics simulation of the glass transition temperature and elastic properties of amorphous polymers PMMA, PMAAM and PMMA co 
PMAAM copolymers," Polymer Bulletin, vol. 73, pp. 30073017, 2016.

[19] Accelrys Software Inc, Materials Studio Modeling Environment, Release6.0, Accelrys Software Inc., San Diego, 2011.

[20] S. Pérez, A. Imberty, S. B. Engelsen et al., "A comparison and chemometric analysis of several molecular mechanics force fields and parameter sets applied to carbohydrates," Carbohydrate Research, vol. 314, pp. 141-155, 1998.

[21] L. Bouzid, S. Hiadsi, M. O. Bensaid, and F. Z. Foudad, "Molecular dynamics simulation studies of the miscibility and thermal properties of PMMA/PS polymer blend," Chinese Journal of Physics, vol. 56, no. 6, pp. 3012-3019, 2018.

[22] N. B. Shenogina and M. Tsige, "Molecular modeling of elastic properties of thermosetting polymers using a dynamic deformation approach," Polymer, vol. 54, no. 13, pp. 3370-3376, 2013.

[23] S. M. Al-Salem and P. Lettieri, "Kinetics of polyethylene terephthalate (PET) and polystyrene (PS) dynamic pyrolysis," International Scholarly and Scientific Research \& Innovation, vol. 4, p. 6, 2010.

[24] A. Brems, J. Baeyens, and C. Vandecasteele, "Polymeric Cracking of Waste Polyethylene Terephthalate to Chemicals and Energy," Raf Dewil, vol. 61, no. 7, pp. 721-731, 2011.

[25] M. Scott Shell, G. Pablo Debenedetti, and Z. Athanassios Panagiotopo-ulos, "A conformal solution theory for the energy landscape and glass transition of mixtures," Fluid Phase Equilibria, vol. 241, pp. 147-154, 2006.

[26] M. J. He, H. D. Zhang, and W. X. Chen, Polymer Physics, Fu Dan University Press, Shanghai, 2007.

[27] J. M. Huang, P. P. Chu, and F. C. Chang, "Conformational changes and molecular motion of poly(ethylene terephthalate) annealed above glass transition temperature," Polymer, vol. 41, no. 5, pp. 1741-1748, 2000.

[28] Y.-h. Wang, W.-h. Wang, Z. Zhang, L. Xu, and P. Li, "Study of the glass transition temperature and the mechanical properties of PET/modified silica nanocomposite by molecular dynamics simulation," European Polymer Journal, vol. 75, pp. 36-45, 2016.

[29] N. M. Alves, J. F. Mano, E. Balaguer, J. M. Meseguer Dueñas, and J. L. Gómez Ribelles, "Glass transition and structural relaxation in semi-crystalline poly(ethylene terephthalate): a DSC study," Polymer, vol. 43, no. 15, pp. 4111-4122, 2002.

[30] D. Rgby and R. J. Roe, "Molecular dynamics simulation of polymer liquid and glass. I. Glass transition," The Journal of Chemical Physics, vol. 87, pp. 7285-7292, 1987.

[31] A. Soldera, "Comparison between the glass transition temperatures of the two PMMA tacticities: A molecular dynamics simulation point of view," Macromolecular Symposia, vol. 133, pp. 21-32, 1998.

[32] J. T. Seltz, "The estimation of mechanical properties of polymers from molecular structure," Journal of Applied Polymer Science, vol. 49, no. 8, pp. 1331-1351, 1993.

[33] M. Garrido, J. R. Correia, and T. Keller, "Effects of elevated temperature on the shear response of PET and PUR foams used in composite sandwich panels,", Construction and Building Materials, vol. 76, pp. 150-157, 2015.
[34] Y.-H. Ko, M. Ahart, J.-H. Ko, and J. Song, "Investigation of polymorphism for amorphous and semi-crystalline poly (-ethylene terephthalate-) using high-pressure Brillouin spectroscopy," Journal of the Korean Physical Society, vol. 70, no. 4, pp. 382-388, 2017.

[35] D. W. Van Krevelen, Properties of Polymers, Their Estimation and Correlation with Chemical Structure, Elsevier, New York, 1976. 